Urbicide: War Violence against Urban Buildings

\title{
Urbicidio: violencia bélica contra las urbes
}

\author{
Arturo Aguirre Moreno \\ Benemérita Universidad Autónoma de Puebla \\ arturo.aguirre@correo.buap.mx \\ Giovanni Perea Tinajero \\ Benemérita Universidad Autónoma de Puebla \\ gpereatinajero@gmail.com \\ DOI: https://doi.org/10.15366/bp.2020.24.016 \\ Bajo Palabra. II Época. № 24. Pgs: 319-336
}


Recibido: 23/01/2020

Aprobado: 12/08/2020

\section{Resumen}

La colaboración enfatiza el carácter corpocéntrico de los edificios desde el giro espacial en la filosofía y el giro forense en la antropología del último siglo. Analiza el cambio en la ejecución de la guerra y la metamorfosis en la forma de habitar humana frente al urbicidio o violencia bélica contra las edificaciones de una urbe. Resalta la relevancia material y socioespacial del inmueble en la íntima relación con el cuerpo humano, lo cual permite señalar que el edificio no es un accidente del habitar ni un daño colateral en el conflicto.

Palabras clave: Urbicidio, hostilidad, violencia en masa, escombro, filosofía contemporánea.

\section{Abstract}

This paper emphasizes the corpocentric nature of buildings from the spatial point of view in philosophy, and forensics in anthropology, of the last century. It analyzes the change in the execution of war and the metamorphosis of human habitation in the face of urbicide or military violence against buildings. It highlights the material and socio-spatial relevance of the property in the intimate relationship with the human body, which makes it possible to point out that the building is not an accident of living or collateral damage in conflict.

Keywords: Urbicide, Hostility, Mass Violence, Rubble, Contemporary Philosophy. 


\section{I}

La época de la destrucción del mundo que abre la Primera Guerra mundial y se extiende en el despliegue de su eficacia letal, ${ }^{1}$ amplitud de geografías de terror, ${ }^{2}$ desarrollo tecnológico de armamento ${ }^{3}$ y estrategias de administración del miedo colectivo ${ }^{4}$ dinamiza sus causas, finalidades y mediaciones criminógenas bajo la acción de una hostilidad creciente. El odio expresado antaño de manera intersubjetiva, se canaliza a través de políticas de Estado sobre grupos étnicos, colectivos vulnerables, disidentes ideológicos, credos, regiones, naciones y otros Estados. Guerras preventivas, guerrillas, intervenciones estatales, genocidios, ecocidios, terrorismo, campos de exterminio, torturas y un amplio espectro de violencias en masa es generado por hostilidades recurrentes, promovidas por los diversos medios de información digital, electrónica e impresa. ${ }^{5}$

Las magnitudes de ese odio colectivo son hoy globales y sus implicaciones en la violencia material innegables entre los grupos de víctimas: hostilidad y violencia fluyen y se expanden por todo el orbe, en la maquinación de sufrimientos sociales sin precedentes. Fin de la historia por un inagotable más de lo mismo, violencia reiterada hacia el porvenir que no ve fin:

Podemos aventurarnos a esbozar aquí una previsión: en el siglo XXI, la guerra no será tan sangrienta como lo fue en el siglo XX, pero la violencia armada, que dará lugar a un grado de sufrimiento y a unas pérdidas desproporcionadas, continuará presente y será un mal endémico y epidémico, por momentos, en gran parte del mundo. Queda lejos la idea de un mundo en paz. ${ }^{6}$

Como lo enuncia Hobsbawm a principios de siglo, hoy los márgenes de la hostilidad, en sus discursividades y motivaciones de aniquilación (que fluyen entre el suicida solitario, las agrupaciones terroristas, los grupos delictivos y los ejércitos

\footnotetext{
${ }^{1}$ Graham, Stephen, "Disruption by Design: Urban Infrastructure and Political Violence", Disrupted Cities When Infrastructure Fails, Nueva York/Londres, Routledge, 2010, pp. 226-262.

2 Elden, Stuard, Terror and Territory. The Spatial Extend of Sovereignty, Minneapolis, University of Minnesota Press, 2009, pp. 1-32.

${ }^{3}$ Llorente, Marta, La ciudad: huellas en el espacio habitado, Madrid, Acantilado, 2015, pp. 442-461.

4 Virilio, Paul, Ciudad pánico. El afuera comienza aquí, Buenos Aires, El zorzal, 2006, pp. 89-101.

${ }_{5}^{5}$ Gerlach, Christian, Sociedades extremadamente violentas. La violencia en masa en el mundo del siglo XX, México, FCE, 2015, pp. 367-381.

${ }^{6}$ Hobsbawm, Eric, Guerra y paz en el siglo XXI, Barcelona, Crítica, 2009, pp. 39-40.
} 
regulares de los Estados), se amplían en múltiples intensidades de conflicto gestadas por los intereses de capitalización de recursos naturales, capitales humanos y geoestrategias globales de posicionamiento bélico, político y mercantil.

El odio como sistema, ${ }^{7}$ es decir, el odio bajo las tecnologías del poder en conjunción con las tecnologías de destrucción, materializadas en armamento, ponen en marcha la transformación epocal de los mecanismos beligerantes ${ }^{8}$ y exhiben las asimetrías generadas por el acceso a determinados recursos y pertrechos. En ese sentido, la velocidad de devastación y la amplia distancia aérea de los ofensores respecto de los objetivos (humanos y no humanos) es privilegio de los países con economías (o alianzas) que pueden permitirse el desarrollo tecnológico y o la adquisición de insumos sofisticados para la destrucción masiva.

La transmutación de la guerra en el último siglo, entonces, en las intrínsecas relaciones que entablan la hostilidad, pánico, tecnología, velocidad, el espacio aéreo, armamento y la violencia en masa, nos permiten llamar la atención sobre los espacios bélicos privilegiados en esta aeroguerra (aviones, misiles, satélites, drones): las ciudades como objetivos bélicos.

\section{II}

EN ESTE HORIZONTE HISTÓRICO de un siglo, las ciudades destacan por su pluralidad, rápido crecimiento, economías materiales y virtuales, por los múltiples espacios que se crean a propósito y aquellos que son resultado de la aglomeración y conjunción de poblaciones. De tal manera, la mayoría de las ciudades que conocemos han sufrido una metamorfosis acelerada, debido a la migración rural o transnacional a los principales centros urbanos del mundo, además de que el desarrollo de las nuevas tecnologías incentiva una alteración no solo en la infraestructura material, sino, a la par, en las relaciones sociopolíticas que promueve. ${ }^{9} \mathrm{Y}$, entre todo ello, no menos importante: la destrucción y reconstrucción reiterada de las ciudades a causa de la elitización urbana (gentrification) o bien a causa de conflictos bélicos de alta intensidad que se desarrollan en los propios espacios urbanos. ${ }^{10}$

\footnotetext{
Veáse Nicol, Eduardo, El porvenir de la filosofí, México, FCE, 1972, pp. 131-133.

${ }^{8}$ Kressel, Neil J., Mass Hate. The Global Rise of Genocide and Terror, Cambridge, Westview, 2002, pp. 1-2.

9 Soja, Edward W., Postmetrópolis. Estudios críticos sobre las ciudades y las regiones, Madrid, Traficantes de sueños, 2009, pp. 545-559. Véase Gutiérrez, R. "En las colinas, las ciudades. Representación política y naturalización del mandato", en Bajo palabra, Revista de Filosofía, II Época, No. 20, 2019, pp. 111-112.

${ }^{10}$ En décadas recientes, los conflictos bélicos se han transformado radicalmente dando lugar a la "guerra urbana" y a tácticas operadas desde una "geometría inversa" que implican una reinterpretación espacial de la ciudad. El arquitecto israelí Eyal Weizman demostró recientemente, en su estudio sobre el conflicto Israelí-Palestino, cómo las instituciones militares se han logrado apropiar del lenguaje y el pensamiento sobre el espacio que la filosofía
} 
Así, consideramos imprescindible realizar desde la filosofía un estudio crítico de la ciudad y las distintas formas en que se le destruye para desarticular conceptual e históricamente - deconstruir, en suma- las implicaciones que tienen para la vida moderna una serie de prácticas de construcción y devastación en la geohistoria reciente del espacio. El estudio de estos procesos no busca solamente integrar o suscribirse a una serie de análisis urbanos, sociológicos y o arquitectónicos; antes bien, propone la apertura de un marco de comprensión para la realidad global actual, históricamente inaugurada por la industrialización capitalista y el surgimiento de la arquitectura moderna funcionalista, así como del saber tecnocientífico instrumental, que tiene la facultad de destruir espacios de aglomeración masiva de vida humana, así como espacios arquitectónicos ${ }^{11}$ históricos representativos para la civilización, occidental y oriental.

En la destrucción de las ciudades resalta el amplio espectro de la infusión de miedos, así como su ser-lugar de concentración poblacional, económica y cultural. De tal manera, el ataque sistemático a los espacios urbanos, en esta época de destrucción, exige la ampliación de la perspectiva del daño a los cuerpos espaciales en la ciudad; ${ }^{12}$ es decir, el conflicto bélico como agente de la destrucción material de las ciudades daña a la vida humana en su condición orgánica, a la par que genera daños en la infraestructura que constituye y es constituyente (simultáneamente) de las formas de vivir, o sea, en las formas de ser habitante de un espacio construido y compartido, eso que Iván Ilich llama "umbral de mutación" de la habitabilidad: ${ }^{13}$ en donde habitar en común ya no es posible. ${ }^{14}$

En tal tenor, resalta el marco histórico de comprensión de las destrucción de las ciudades desde la revaloración conceptual de teorías corpocéntricas. ${ }^{15}$ Es decir, el cuerpo reconsiderado en su diversidad espacial: geométrica (longitud, altitud y profundidad), matemática (masa, peso y volumen), antropológica (relación, comunicación, símbolo y socialización) y forense (cuerpo dañado al que se le ha cometido un delito). Consecuentemente, la atención recae en la violencia urbicida; una violencia que atenta contra la ciudad, en la integridad de sus cuerpos monumen-

propone para generar estrategias de guerra. Esta nueva interpretación militar del espacio comprende a la ciudad como un espacio instrumental, es decir, como el vehículo o el medium para practicar la guerra, dando lugar a la guerra urbana como paradigma contemporáneo de la guerra. Véase Weizman, Eyal, A través de los muros. Cómo el ejército israeli se apropió de la teoría crítica postmoderna y reinventó la guerra urbana, Madrid, Errata Naturae, p. 52 y passim.

11 Weizman, Eyal, Forensic Architecture. Violence at the Threshold of Detectability, Nueva York, Zone Books, 2017, pp. 78-82.

12 Ibid., pp. 51-54.

${ }_{13}$ Véase un planteamiento similar en Esquirol, Josep Maria, La resistencia intima. Ensayo de una filosofía de la proximidad, Barcelona, Acantilado, 2015, pp. 39-44. Donde el autor trata el asunto de la habitabilidad compartida mediante el paradigma de la casa, aquel lugar que materializa la reunión de sus miembros.

${ }^{14}$ Illich, Iván, "La reivindicación de la casa”, El País. (5 jun 1983), s/p.

15 Coward, Martin, Urbicide. The Politics of Urban Destruction, Nueva York, Routlegde, 2009, pp. 12-13. 
tales: casas, edificaciones públicas, calles, plazas, puentes y corporalidades que son constituyentes del habitar urbano.

\section{III}

En el sigLo XX, de las grandes Guerras Mundiales y de una expansión de la violencia en diversas manifestaciones marcadas también por la Guerra fría, diversas revoluciones y los insurgentes movimientos sociales, se creía que la afectación o destrucción de los espacios donde acontecía la violencia era una dinámica circunstancial a su ejercicio, resultado de un dańo colateral. Sin embargo, el concepto de urbicidio en los últimos cincuenta años ha modificado sustancialmente esta idea, propia de quienes ejercen la violencia y no solo de las víctimas que la padecen. Según Martin Coward, el uso del concepto de urbicidio adquirió mayor relevancia durante la segunda mitad del siglo XX; pues con este se hacía referencia a un daño colateral causado a civiles durante la guerra de Bosnia en 1992. ${ }^{16}$ En esta se vieron destruidos una serie de inmuebles, los cuales atestiguaron que aquello que pudo ser considerado como un daño colateral a causa de la guerra, más bien era el derrumbe y destrucción de las condiciones de posibilidad para habitar una ciudad. Es decir, el daño colateral no es consecuencia de una guerra, por el contrario, es su daño principal. Según Coward:

[...] la devastación del entorno construido se manifiesta (aunque no limitado a) en la destrucción de puentes, mezquitas e iglesias, grandes tiendas departamentales, manzanas de apartamentos, edificios públicos, hoteles y espacios públicos (como parques), que fueron más que un daño colateral. ${ }^{17}$

Así, se puede constatar que la violencia deliberada contra el espacio edificado que acontece en un urbicidio afecta la cualidad arquitectónica material de una urbe cuando hace de sus construcciones y edificios sus objetivos de destrucción. ${ }^{18}$ Derivada de este modo, de destrucción en niveles de devastación y demolición total, aparece la producción de escombro. Producto de una materialidad destruida,

\footnotetext{
${ }_{16}$ Para Martin Coward, uno de los teóricos que trata el problema del urbicidio, la guerra de los Balcanes es un ejemplo de cómo la población civil participó de manera pasiva, como victimas inermes de un conflicto armado. Una de las referencias de este hecho a las cuales hace alusión es la obra de Ribarevi-Nikolic y Juric Mostar '92 - Urbicide. Donde, como bien lo indica el autor, las imágenes presentadas en Mostar '92 evidencian un daño directo al ambiente urbano. Véase Coward, Martin, Urbicide. The politics of urban destruction, Nueva York, Routledge, 2009, p. 35.

17 Ídem.

${ }^{18}$ Graham, Stephen, "Disruption by Design: Urban Infrastructure and Political Violence", Disrupted Cities When Infrastructure Fails, op. cit., p. 113.
} 
amorfa y fragmentada, un residuo de la destrucción de una ciudad con el que sus habitantes tienen relación en su dimensión arquitectónica, pero sobre todo vital, desgarrada y destruida también por los nexos culturales y afectivos que la sostenían como espacio de relación compartido.

Las dinámicas de violencia donde las ciudades son el objetivo a dañar, las convierten en protagonistas y a su vez en víctimas de un ambiente que se vulnera por un aniquilamiento de la corporalidad (de cuerpos humanos, arquitectónicos, entre otros que constituyen el tejido urbano). Es decir, el aniquilamiento de su existencia material hace que estos cuerpos pierdan forma y sentido una vez convertidos en simple escombro. Por ejemplo, en la Segunda Guerra Mundial muchos de los edificios destruidos quedaron irreconocibles reducidos a escombros. En su intento por realizar una arquitectura forense, W. G. Sebald trata de identificar, a partir de sus restos, los edificios destruidos en esa época; sin embargo, los niveles de devastación habían sido tan altos que algunos solo se podían registrar por la cantidad de sus escombros, cuantificados en metros cúbicos de concreto, acero, vidrio, etcétera. ${ }^{19}$

Con ello, los edificios aparecen si bien, como cuerpos constitutivos del tejido urbano, también como víctimas en un conflicto bélico, cuestión que no solo tiene que ver con el recuento de los daños causados. Además, resalta por la recuperación de la memoria de un espacio habitado previo a su destrucción que espera encontrar las marcas y huellas de sus habitantes que se resisten a desaparecer entre la homogeneidad de sus escombros. Algunos análisis en la guerra de la llamada Franja de Gaza, como el de Eyal Weizman, dan cuenta que alrededor de 1400 personas fueron asesinadas y 15000 edificios destruidos o dańados en el ataque a Gaza de diciembre 2008 a enero 2009; lo cual muestra la intrínseca relación entre la proporción de muertos con los edificios; ${ }^{20}$ muestra, también, que las dinámicas de violencia bélica se han enfocado, en la generación de daño a partir de la destrucción de los edificios por encima de las víctimas humanas.

El urbicidio ejercido contra espacios construidos supone que sus estragos sean efectivos para desarticular formas de vida en común, así porque entiende que el espacio urbano se constituye como un tejido de elementos comunes que están en función los unos de otros. ${ }^{21}$ En este sentido, el objetivo de ataque son los edificios,

${ }_{19}$ Sebald, Winfried, On the Natural History of Destruction, Nueva York, Random House, 2003, p. 5.

${ }^{20}$ Weizman, Eyal, The Least of All Possible Evils. Humanitarian Violence from Arendt to Gaza, Londres/Nueva York, Verso, 2011, p. 125. Weizman es miembro y fundador de la agencia de investigación Forensic Architecture, dedicada al estudio de víctimas de violencia a partir de evidencias provenientes de distinta índole, que van desde cuerpos humanos, edificios o infraestructuras destruidas, testimonios oficiales y civiles, hasta el análisis de datos virtuales en redes sociales. Esto con el fin de devolver un análisis contraforense, es decir, distinto al que ofrecen los organismos de Estado, de los cuales se sospecha pueden encubrir la veracidad y validez de las evidencias.

${ }^{21}$ Cerdà, Ildefons, Teoría general de la urbanización y aplicación de sus principios y doctrinas a la reforma y ensanche de Barcelona, Madrid, Imprenta espańola, 1867, p. 29. 
cuerpos materiales que son nudos los cuales mantienen unido y articulado al tejido del espacio urbano. ${ }^{22}$ Frente a esto, la destrucción de cualquier ambiente urbano, parcial o totalmente, es una forma de destrucción del espacio, en cualquiera de los niveles de urbanización que le acaecen, llámense casa, aldea, pueblo, ciudad o metrópoli. Todas estas formas de urbanización pueden ser víctimas de la destrucción de su espacio, por la cualidad dañina que le constituye a la violencia urbicida.

Las ciudades se han mantenido como una unidad de edificaciones diversas, en su aspecto corporal, en relación constante y simultánea con sus habitantes. Con el daño al espacio construido (llámese domo, urbs, ville) ${ }^{23}$ aparecen arquitecturas del terror reflejadas en lo inhóspito del escombro.

De esta manera, la producción de espacios de violencia configura una nueva fisonomía y textura urbanas marcadas principalmente por lugares de muerte y destrucción. De tal modo que las ciudades se van configurando y construyendo conforme y paralelamente con las prácticas bélicas. Es decir, parte de su arquitectura se constituye en función de la recepción y asimilación de la violencia. Además, el comportamiento de los habitantes resulta ser hostil y doloroso a la vez, tienen que cambiar su manera habitar un espacio urbano desfigurado por la violencia; habitando una arquitectura de la destrucción y en la medida de lo posible diseñada para una ciudad en constante resistencia a la guerra. Aquí aparece lo que Andrea Cavalletti denomina como la inversión de la arquitectura, ${ }^{24}$ generada por la construcción del espacio por y para la violencia. Resulta también un espacio urbano contrario a lo que originalmente se había pensado: uno hecho a partir de una arquitectura que protege y hace frente a la intemperie.

\section{IV}

LA CONSTITUCIÓN DE LA CIUDAD no es solamente un conjunto de cuerpos y materias (metales, piedras, maderas o vidrios) cuidadosamente planeadas, fragmentadas y diseñadas. Esta materialidad convive con sus habitantes, es parte de sus prácticas espaciales, y da sentido y orientación a las mismas. La conforman luga-

\footnotetext{
22 Según el político y urbanista catalán Ildefons Cerdà los procesos de urbanización, es decir, de construcción del espacio, se ha producido de manera distinta a lo largo de la historia. Sin embargo, lo que permite hablar propiamente de una urbe que es el tejido que caracteriza a la conformación y relación sus partes. Urbanización dice Cerdà, señala "[...] este maremágnum de personas, cosas, intereses de todo género, de mil elementos diversos que a primera vista parecen funcionar cada cual a su manera e independientemente de los otros, mientras que al observarlos con detenimiento y espíritu crítico se nota que, quizás ejerciendo uno sobre otro una acción muy directa, están en contante relación y forman, en consecuencia, una unidad”. Ídem.

23 Sennett, Richard, Construir y habitar, Barcelona, Anagrama, 2019, p. 9.

${ }^{24}$ Cavalletti, Andrea, Mitología de la seguridad. La ciudad biopolítica, Buenos Aires, 2010, p. 42.
} 
res que se distinguen y que al mismo tiempo son comunes entre los habitantes. Su destrucción provoca todo lo contrario: un espacio sin referencialidad ni orientación. Pone en crisis las prácticas espaciales y, con ello, la posibilidad de establecer relaciones de comunidad o habitar en común. ${ }^{25}$ Sobre esto, vale la pena preguntar si ¿la destrucción de la ciudad, en términos materiales, reducida a los escombros, implica el fin de las prácticas espaciales? $\mathrm{O}$, en su defecto, ¿genera otras prácticas alternativas que resisten o conviven con el espacio destruido? Pues frente a estas prácticas totalitarias de espacio bélico, la idea de una ciudad como espacio de seguridad desaparece.

La guerra se presenta entonces como una práctica llanamente espacial, donde las dimensiones del espacio no se reducen al espacio público, privado ni al espacio construido. Más bien muestra que, ahí, la producción y alteración espacio-corporal en el daño y destrucción genera de la ciudad un producto de guerra. En su dimensión arquitectónica, la ciudad es un conjunto elementos corporales que generan un volumen, es decir, generan espacios o ambientes. Esto abre la necesidad de pensar a la ciudad en todas sus variantes interpretativas, que le son inherentes a dicho volumen, y que también son parte de las estrategias de violencia, pues la dimensionan no solo en su horizontalidad o verticalidad, sino, también en su espacio aéreo, subterráneo, desde sus lados frontales o posteriores. Lo cual rompe la idea de que la guerra se lleva a cabo frente a frente; más bien, muestra la relatividad del espacio urbano, concebido en función de sus prácticas espaciales; señalando distintos lados de una misma ciudad: sus edificios y calles, pero también sus umbrales: sus grietas, boquetes, edificios destruidos o derrumbados, sus túneles, sus fosas, e incluso a través de los muros y sobre sus campos de escombros. De esta manera, la guerra se devela como una forma de producción del espacio; espacios de terror y violencia que muestran que la ciudad contemporánea aloja, resiste y sufre las violencias más brutales.

Caracterizada como una forma de violencia bélica, la destrucción del espacio urbano, ya sea por bombardeos, proyectiles, demoliciones por buldóceres, etcétera, es una práctica de devastación que produce escombro. El escombro se revela, por ende, como los restos de una nueva víctima que aparece con la guerra urbicida: el edificio.

\footnotetext{
25 Aquí es importante tener presente la condición ontológica que se mantiene como cualidad inherente a la existencia de cualquier ente corpóreo. Algunos autores como Jean-Luc Nancy hablan de un ser-en-común para referirse a esta relación entre los cuerpos. Esta noción debe ser fundamental para comprender la manera en que ontológicamente el hombre se encuentra en relación con todo lo que lo rodea; hay una disposición a relacionarse que no tiene que fundamentarse más que con la forma de ser del hombre como un ser en común. Véase Nancy, Jean-Luc, "Conloquium”, en Esposito, R., Communitas: Origen y destino de la comunidad, Buenos Aires, Amorrortu editores, 2003, p. 16.
} 


\section{V}

PeRo ¿Qué es UN EDIFICIO? El edificio aparece como una huella vertical de la corporalidad construida en común, rastro y testimonio de que otros estuvieron aquí, herencia protegida y protectora para los que vendrán, impronta tempoespacial de nuestro cuerpo en sus formas de morar y hacer mundo en la geohistoria de los pueblos. Su destrucción, por tanto, atenta entonces contra esta memoria y vestigio corporal que parecía marcar el espacio por sus habitantes.

Desde la aproximación forense (arquitectónica y filosófica) pueden identificarse ahora los edificios como cuerpos que dańados por la violencia muestran una herida, un trauma que da cuenta del daño que se les ha cometido. ${ }^{26}$ Así, un impacto de proyectil en los muros, un edificio arruinado o un montón de escombros son evidencia de un espacio herido, alterado menor o mayormente. En dimensiones forenses, cada práctica urbana que marca el espacio por medio de la violencia devela la cualidad de víctima y señala al victimario por los pertrechos utilizados para la violencia que ejecutó. Es, se sigue, la evidencia que habla de una violencia acontecida, y también de la manera en que estos escombros afectan la vida de sus habitantes. Porque el espacio que se habita no es un espacio neutral y abstracto, más bien, aparece con sentido a partir de las relaciones que se configuran entre sus cuerpos. Al destruirse, se muestra como un espacio de terror, un espacio afectado por la violencia y también afectante para quienes lo logran habitar. ${ }^{27}$

El espacio herido, muestra también un doble daño: a sus habitantes y al mismo tiempo a sus espacios construidos, ya que el urbicidio opera a partir de la destrucción del espacio y no solo de muerte o asesinato de habitantes. Como materia forense ruina y escombro son evidencia de daño y violencia, están inscritos en una escena del crimen y en ese sentido son literalmente testigos que dan cuenta de lo ocurrido. Según Weizman:

Con el incremento de la urbanización del conflicto, las representaciones del ambiente construido vienen a ser llamadas como evidencia en cortes internacionales, tribunales y

\footnotetext{
26 "En el contexto de las investigaciones sobre crímenes de guerra, las prácticas forenses emergidas a mitad de la década de 1980 desde la antropología forense -la aplicación de la ciencia de la antropología física en escenas legales, la mayoría de ellos en relación con restos de una víctima- y en la cristalización de una nueva disciplina de arqueología forense, que aplicó principios arqueológicos, técnicas y metodologías en la excavación de vestigios de guerra". En Weizman, Eyal, The Least of All Possible Evils. Humanitarian Violence from Arendt to Gaza, op. cit., p. 136.

27 Algunos planteamientos, como el Jane Bennett, señalan en su concepto de materia sensitiva (sensitive matter) la capacidad afectante y afectable de un cuerpo material. Según la autora, un cuerpo es maleable en tanto que objeto material, pero también dicha materia tiene la capacidad de afectar otros cuerpos. En este caso, la clara afectación al tratar de habitar un espacio destruido evidencia la tesis de Bennett. Véase Bennett, Jane, Vibrant Matter. A political Ecological of Things, Durham/Londres, Duke University Press, p. 26.
} 
medios. Los datos geoespaciales e imágenes en alta resolución satelital de edificios destruidos son a menudo usados como evidencia en la corte [...] donde al comienzo del proceso, fragmentos de edificios (y fotografías de estos) desde casas privadas, jardines y almacenes, permiten argumentar una versión diferente de los hechos, usando el escombro encontrado y alegado como evidencia para sostener reclamos. ${ }^{28}$

Por otro lado, desde una mirada espacial se pueden asir las dimensiones del daño al espacio urbano a partir de su destrucción. Consecuente ocurre una alteración social por los nexos y espacios compartidos en las dinámicas de habitar urbano.

De ahí que hablar de urbicidio refiera al daño y mutación de las condiciones de habitabilidad, las habitaciones y hacia los habitantes, en las relaciones corporales de proximidad (espacialidad) y simultaneidad (temporalidad) en una ciudad. De este modo, cualquier agente urbicida, tiene que planear, como en su momento lo hace para su construcción el arquitecto, urbanista o ingeniero civil, estrategias de ataque en que su aplicación provoquen una afectación en el espacio habitado.

Este saber es usado con fines militares aprovechando el espacio arquitectónico como parte de una táctica o estrategia en tiempos de guerra. Hacer este uso del espacio indica una inversión de la arquitectura; por lo cual, términos como el de geometría urbana inversa ${ }^{29}$ reflejan la manera como operan algunas prácticas bélicas hoy día. Teóricos como Eyal Weizman indican que esta geometría permite una interpretación del espacio urbano desde la perspectiva militar, donde el uso de este sirve al éxito de una batalla. En una entrevista realizada por el mismo Weizman al oficial Aviv Kochavi, filósofo, arquitecto y estratega militar, dice lo siguiente en relación con la interpretación del espacio:

La cuestión es ¿`cómo interpreta usted la avenida? ¿La interpreta como un lugar que sirve para llegar a algún lugar como suelen hacer todos los arquitectos y urbanistas, o la interpreta más bien como un lugar por el que está prohibido cruzar? Todo es cuestión de interpretación. Nosotros interpretamos la avenida como un lugar que está prohibido cruzar y la ventana como un lugar por el que está prohibido mirar, porque hay un arma esperándonos en la avenida y bombas trampa detrás de las puertas. El enemigo interpreta el espacio en términos tradicionales y yo no estoy dispuesto a obedecer su interpretación y, al hacerlo, caer en sus trampas. ${ }^{30}$

El testimonio de Kochavi revela una nueva manera de concebir la guerra propia de los conflictos del actual siglo XXI, donde estas no solo se han llevado del campo a

\footnotetext{
28 Weizman, Eyal, The Least of All Possible Evils. Humanitarian Violence from Arendt to Gaza, op. cit., p. 137.

29 Weizman, Eyal, A través de los muros. Cómo el ejército israeli se apropió de la teoría crítica postmoderna y reinventó la guerra urbana, Madrid, Errata Naturae, op. cit., p. 51.

30 Ibid., p. 52.
} 
la ciudad, sino que la misma ciudad se ha constituido como el nuevo escenario bélico, en lo que Weizman ha denominado como guerras urbanas. ${ }^{31}$ De manera inversa, la guerra ha tenido que adaptarse al entorno urbano y al mismo tiempo la ciudad se ha configurado con sus dinámicas bélicas. Aparece con ello "[...] la última forma posmoderna de la guerra [donde] los oficiales al mando encuentran muy difícil preparar escenarios bélicos o diseñar planes de vía única. Los civiles se convierten en combatientes y los combatientes vuelven a ser civiles". ${ }^{32}$ Así, se abre un horizonte de ideas sobre el espacio para dar cuenta de las múltiples dimensiones que adquieren de acuerdo a cada interpretación. Esto requiere de un sentido crítico y hasta de conceptualizaciones filosóficas que propician formas distintas de entender el espacio. En este caso, bajo un enfoque violento centrado en la configuración del escenario bélico:

La referencia a la necesidad de interpretar el espacio, e incluso de reinterpretarlo, como condición necesaria del éxito de la guerra urbana, desvela la presencia de su pensamiento de una teoría del lenguaje posmoderna, posestructuralista. La guerra, de acuerdo con el lenguaje sofisticado y aséptico de Kochavi, es una cuestión de lectura y (conceptualmente) de deconstrucción del entorno urbano existente, incluso antes del comienzo de la operación. ${ }^{33}$

En ese sentido, esta forma de urbicido genera nuevos paisajes urbanos vinculados al lado destructivo de las prácticas espaciales: una producción destructiva del espacio, que genera un nuevo paisaje y ambiente mayormente inhóspito. Las estrategias del General Kochavi llevadas a cabo sobre la ciudad de Nablus, Cisjordania, revelan la relatividad de las concepciones de espacio, en función de sus prácticas. Esta geometría inversa se pone al servicio del diseño y proceder de las estrategias militares, nutrida por las teorías estructuralistas de la filosofía de Deleuze y Guattari. Así, queda claro que la producción urbicida del espacio reflejada en la guerra urbana es un acto intencionado, premeditado y razonado con el fin de provocar daño en sus víctimas.

\section{VI}

EN TAL TENOR, la destrucción violenta del espacio urbano, en específico, mediante dinámicas bélicas, demuestra que el escombro, en tanto que resultado y consecuencia material, es propiamente un producto de guerra. Aquí le llamamos producto porque resulta de una práctica espacialmente violenta que produce un espacio de

\footnotetext{
31 Ibid., p. 51.

32 Ibid., p. 18.

33 Ibid., p. 54.
} 
destrucción a partir de la corporalidad previamente edificada. Las dinámicas de guerra contemporánea han tenido como escenario al espacio urbano, haciendo que sus operaciones de muerte y destrucción sean causa de que la ciudad ahora sea vista como un espacio para el despliegue de estrategias e inversiones espaciales. Las ciudades con dichas características parecen espacios prohibidos, zonas de violencia e inseguridad constante que pese a esta dificultad aún subsisten; frente a esto ¿cómo es habitable o bajo qué posibilidades se puede habitar una ciudad producida por la guerra?

Por otro lado, ¿qué espacios configura el escombro y cómo altera el ambiente urbano? Genera un nuevo paisaje urbano que adquiere una connotación forense por la destrucción violenta y dimensión de víctima que adquieren los edificios destruidos. Considerar la producción violenta del escombro como una nueva estrategia de violencia exige pensar ¿qué es exactamente el escombro o cómo se identifica? ¿qué es lo que nos puede decir de la destrucción urbana? Y, sobre todo, ¿de qué manera afecta la experiencia de habitar un espacio? Como tal, los escombros son fragmentos que no tienen una cualidad o forma definida, más bien, se caracterizan como despojos y desperdicios inútiles que se tienen que limpiar. Frente a esto hay que distinguirlo de la ruina.

Aunque escombro y ruina están relacionados porque son producto de una destrucción, es necesarios ver sus particularidades. La ruina desde su propia definición indica una construcción (inmueble o monumento) que ha venido a menos y dejó de cumplir su propósito (habitar, recrear, albergar, etcétera). Deteriorada por el paso del tiempo, le sobreviven ciertas partes estructurales que permiten la recreación imaginaria de sus funciones, relevancia y relación con los cuerpos humanos. Es decir, muestra vestigios de lo que algún día fue un edificio pleno, funcional y referencial en el tejido urbano.

Por otro lado, la ruina es objeto complejo de la destrucción: sus cimientos y muros guardan la memoria de los habitantes, es decir, se trata de la percepción que mueve la sensibilidad sociomemorial y exalta el acontecimiento de su erección y su derrumbe parcial. ${ }^{34}$ En ese sentido, la ruina es lo que queda después de la destrucción, lo que María Zambrano llama "la victoria del fracaso", 35 aquello que logró resistir al tiempo. Es también muestra de la destrucción que la ha constituido, con lo cual queda como "la traza de algo humano vencido y luego vencedor del paso del tiempo". ${ }^{36}$

\footnotetext{
${ }^{34}$ Hermosa Andújar, Antonio, "Volney ante las ruinas de Palmira: lo que pasa y no pasa con el tiempo", Bajo Palabra, Revista de Filosofía, II Época, No. 18, 2018, p. 120.

35 Zambrano, María, El hombre y lo divino, México, FCE, p. 254.

36 Ibid, p. 253.
} 
En contextos bélicos, específicamente, la ruina se muestra como un ente arquitectónico testimonial que aloja entre sus paredes las consecuencias destructivas de la violencia: "[...] Un edificio destruido señala más que el hecho de su destrucción; contiene información acerca de sus medios. Las ruinas son una forma de medio. Estas almacenan y, con la ayuda de sus 'interpretes', también transmiten información sobre los efectos de procesos históricos" ${ }^{37}$ En otras palabras, también son evidencia tangible de la manera en que se ha ejercido y padecido la violencia.

A diferencia de la ruina, el escombro tiene la particularidad de no permanecer a través del tiempo. La ruina parece sobrevivir, muestra que algo quedó; el escombro, más bien, tiene que ser barrido como cuerpo sobre en el que el victimario se ha ensañado hasta desarticular su integridad corporal. En idioma español, comúnmente decimos escombro al desecho, despojo o residuo del material de construcción destruido. En ese sentido, el escombro se muestra como un montón de piedras, cenizas, vidrios, entre la variabilidad de materiales, que tiene que ser retirado. El edificio reducido a escombro está sometido a su desaparición y con ello se le niega toda forma de huella o trascendencia que dé cuenta de que en algún momento existió. Aunque, en principio ambos, escombro y ruina, indican la fragilidad de lo edificado; el escombro, por su parte, muestra el daño irreversible en la destrucción del espacio. A diferencia de la ruina, el escombro no se puede reconstruir y mucho menos reivindicar, su fragmentación es tal que en su homogénea forma no queda más que limpiarlo.

\section{Conclusiones}

EN ESTE SENTIDO, el edificio como víctima en los procesos de guerra urbicida contemporánea (aeroguerra, tecnología armamentística, estrategias de destrucción de las condiciones de habitar sobre edificios e insfraestructura caracterizados por su diversidad -bibliotecas, museos, puentes-) exhibe al escombro como la consumación letal de la desrealización constructiva de los cuerpos monumentales. Esto es, por un lado, demuestra la evidente destrucción de los edificios, por otro, altera el habitar cotidiano de las personas, donde se complica sobrevivir sin la ciudad que había construido de manera histórica y colectiva. ${ }^{38}$ De modo que transitar entre escombros (sin posibilidad de refugio en ellos) implica convivir con la ausencia de la memoria de una ciudad destruida. En su defecto, la insoportable ausencia de es-

\footnotetext{
37 Weizman, Eyal, The Least of All Possible Evils. Humanitarian Violence from Arendt to Gaza, op. cit., p. 137.

38 Llorente, Marta, La ciudad: huellas en el espacio habitado, op. cit., p. 9.
} 
pacio construido obliga a la reconstrucción, reparación o incluso migración, como muestran los casos de las ciudades sirias actuales.

Como vemos, si bien, a lo largo de la historia las ciudades han sufrido ataques y violencias brutales, las últimas dinámicas bélicas (como lo anunciaba Hobsbawm) han tenido mayor precisión en sus modos de ejecución e impacto mayor, lo cual da a entender que la guerra se está llevando a cabo en los espacios urbanos, modificando constantemente los umbrales de habitar conocido. Un habitar complicado ante la violencia constante, ya sea esta, criminal, delincuencial, terrorista o bélica. Estas formas de violencia merman, eliminan o inhiben las capacidades y despliegues de habitar en las prácticas corpoespaciales. 


\section{ReFERENCIAS Bibliográficas}

Bennett, Jane, Vibrant Matter. A political Ecological of Things, Durham/Londres, Duke University Press, 2010. DOI: https://doi.org/10.1215/9780822391623

Cavalletti, Andrea, Mitología de la seguridad. La ciudad biopolítica, Buenos Aires, Adriana Hidalgo, 2010.

Cerdà, Ildefonso, Teoría general de la urbanización y aplicación de sus principios y doctrinas a la reforma y ensanche de Barcelona, Madrid, Imprenta española, 1867.

Coward, Martin, Urbicide. The Politics of Urban Destruction, Nueva York, Routlegde, 2009. DOI: https://doi.org/10.4324/9780203890639

Elden, Stuart, Terror and Territory. The spatial Extend of Sovereignty, Minneapolis, University of Minnesota Press, 2009.

Esquirol, Josep Maria, La resistencia intima. Ensayo de una filosofía de la proximidad, Barcelona, Acantilado, 2015.

Gerlach, Christian, Sociedades extremadamente violentas. La violencia en masa en el mundo del siglo XX, México, FCE, 2015.

Graham, Stephen, Cities under Siege. The New Military Urbanism, Nueva York, Verso, 2011.

Graham, Stephen, Disruption by Design: Urban Infrastructure and Political Violence. Disrupted Cities When Infrastructure Fails, Nueva York/Londres, Routledge, 2010. DOI: https://doi.org/10.4324/9780203894484

Gutiérrez, R., "En las colinas, las ciudades. Representación política y naturalización del mandato", en Bajo palabra, Revista de Filosofía, II Época, No. 20, 2019 pp. 107-124. DOI: http://doi.org/10.15366/bp2019.20.006

Hermosa Andújar, Antonio, "Volney ante las ruinas de Palmira: lo que pasa y no pasa con el tiempo", en Bajo Palabra, Revista de Filosofía, II Época, No. 18, 2018, pp. 117-150. DOI: https://doi.org/10.15366/bp2018.18.006

Hobsbawm, Eric, Guerra y paz en el siglo XXI, Barcelona, Crítica, 2009.

Illich, Ivan, "La reivindicación de la casa" en El País. (5 jun 1983), recuperado de https://elpais.com/diario/1983/06/05/opinion/423612014_850215.html

Kressel, Neil, Mass Hate. The Global Rise of Genocide and Terror. Cambridge, Westview, 2002. 
Lefebvre, Henri, La producción del espacio, Madrid, Capitán Swing, 2013.

Llorente, Marta, La ciudad: huellas en el espacio habitado, Madrid, Acantilado, 2015.

Nancy, Jean-Luc, "Conloquium”, en Esposito, R., Communitas: Origen y destino de la comunidad. Buenos Aires, Amorrortu editores, 2003.

Nicol, Eduardo, El porvenir de la filosofía. México, FCE, 1972.

Sebald, Winfried, On the Natural History of Destruction, Nueva York, Random House, 2003.

Sennett, Richard, Construir y habitar, Barcelona, Anagrama, 2019.

Soja, Edward W., Postmetrópolis. Estudios críticos sobre las ciudades y las regiones, Madrid, Traficantes de sueños, 2009.

Virilio, Paul, Ciudad pánico. El afuera comienza aqui, Buenos Aires, El zorzal, 2006.

Weizman, Eyal, $A$ través de los muros. Cómo el ejército israeli se apropió de la teoría crítica posmoderna y reinventó la guerra urbana, Madrid, Errata naturae, 2012.

Weizman, Eyal, Forensic Architecture. Violence at the Threshold of Detectability, Nueva York, Zone Books, 2017. DOI: https://doi.org/10.2307/j.ctv14gphth

Weizman, Eyal, The Least of All Possible Evils. Humanitarian Violence from Arendt to Gaza, Londres/Nueva York, Verso, 2011.

Zambrano, María, El hombre y lo divino, México, FCE, 1973.

DOI: https://doi.org/10.15366/bp.2020.24.016

Bajo Palabra. II Época. № 24. Pgs: 319-336 
